\title{
Environmental Taxation and Revenue for Development
}

\author{
Agnar Sandmo *
}

December 2003

\begin{abstract}
This paper considers the role of global environmental taxes both as instruments for improving the global environment and as a source of revenue for funding economic development. It reviews the general case for environmental taxes and the particular issues that arise for the adoption of such taxes in an international setting without a single jurisdiction. It also discusses the possibilities for political acceptance of such taxes when tax revenue is linked to the goal of economic development. The revenue potential of global environmental taxes is evaluated with special reference to a global carbon tax. It is found that this tax alone has the potential to raise sufficient revenue to finance the United Nations' Millennium Development Goals.
\end{abstract}

Keywords: environment, taxation, carbon tax, consumption

JEL classification: $\mathrm{H} 23, \mathrm{H} 87, \mathrm{O} 13$

\section{Copyright (C) UNU-WIDER 2003}

* Norwegian School of Economics and Business Administration, Bergen; email: Agnar.Sandmo@nhh.no

This study has been prepared within the UNU-WIDER and UN-DESA joint project on Innovative Sources for Development Finance, which is directed by Anthony B. Atkinson, and was presented at the WIDER Conference on Sharing Global Prosperity in Helsinki, 6-7 September 2003.

UNU-WIDER gratefully acknowledges the support to the project from the United Nations Department of Economic and Social Affairs (UN-DESA). UNU-WIDER also acknowledges the financial contributions to the 2002-2003 research programme by the governments of Denmark (Royal Ministry of Foreign Affairs), Finland (Ministry for Foreign Affairs), Norway (Royal Ministry of Foreign Affairs), Sweden (Swedish International Development Cooperation Agency-Sida) and the United Kingdom (Department for International Development). 


\section{Acknowledgements}

This paper has been prepared for the WIDER project on Innovative Sources for Development Finance. I am indebted to the project participants, especially Tony Atkinson and Robin Boadway, for their comments on an earlier version, and to Ottar Mæstad and David Wildasin for helpful suggestions.

The World Institute for Development Economics Research (WIDER) was established by the United Nations University (UNU) as its first research and training centre and started work in Helsinki, Finland in 1985. The Institute undertakes applied research and policy analysis on structural changes affecting the developing and transitional economies, provides a forum for the advocacy of policies leading to robust, equitable and environmentally sustainable growth, and promotes capacity strengthening and training in the field of economic and social policy making. Work is carried out by staff researchers and visiting scholars in Helsinki and through networks of collaborating scholars and institutions around the world.

www.wider.unu.edu publications@wider.unu.edu

UNU World Institute for Development Economics Research (UNU-WIDER)

Katajanokanlaituri 6 B, 00160 Helsinki, Finland

Camera-ready typescript prepared by Liisa Roponen at UNU-WIDER

Printed at UNU-WIDER, Helsinki

The views expressed in this publication are those of the author(s). Publication does not imply endorsement by the Institute or the United Nations University, nor by the programme/project sponsors, of any of the views expressed. 


\section{Introduction}

This paper considers the possible role of environmental taxes for economic development. This role is quite complex and has not so far been widely discussed in the literature. It is therefore useful to start with a review of the basic economic insights in the field of environmental taxation in order to prepare the ground for the application of the theory to problems of economic development and the global environment.

Section 2 below starts with a review of the welfare economics of environmental taxation in a single closed economy; analytical details are provided in Appendix A. Section 3 discusses alternatives to taxes as instruments of environmental policy, considering both fixed and transferable quotas. Section 4 is a review of the double dividend issue, which has received much attention in recent literature, while section 5 considers the extent to which distributional concerns should be reflected in the design of environmental policy. Since much of the literature in this area relates to the economies of industrialized countries, section 6 takes up some special problems in its application to developing economies. Section 7 extends the analysis from the single country to the case of global externalities where each individual country is affected by the environmental pollution of all other countries; a formal analysis in the context of a two-country model is in Appendix B. The political economy of global environmental taxes is considered in section 8, which also compares alternative tax designs with regard to the equityefficiency trade-off. After a brief discussion of some practical problems of tax collection in section 9, section 10 evaluates the revenue potential of such taxes with special reference to the carbon tax. Some concluding remarks are collected in the final section of the paper.

\section{The general theory of environmental taxation}

A basic economic insight is that a competitive economy, under ideal conditions, will generate a socially efficient or Pareto optimal allocation of private goods, meaning that it is not possible to reallocate resources in such a way that everyone becomes better off.

In partial equilibrium terminology, an efficient allocation of private goods is achieved when, first, the marginal cost of producing a commodity is the same for all producers; this requirement is what is known as production efficiency. Second, the marginal willingness to pay for the commodity - the marginal benefit — should be the same for all consumers, ensuring consumption efficiency. Third, the marginal cost of production should equal the marginal willingness to pay; this final requirement ensures overall Pareto optimality. In an ideal competitive environment, optimizing behaviour by firms and consumers will ensure that marginal costs and marginal benefits will be equated to the equilibrium prices for all goods. Thus, a competitive equilibrium is a Pareto optimum, and there is no waste of resources.

One element of the 'ideal conditions' requirement is the absence of external effects. Originally introduced by Alfred Marshall, the externality concept was further developed by Arthur C. Pigou (1920), who also pioneered the application of the theory to environmental problems in the modern sense. In recent decades, the increasing 
awareness of the environmental damage caused by modern societies has greatly increased the importance of externality theory as a tool for applied policy analysis. ${ }^{1}$

Environmental externalities may be both positive and negative, but we focus here on the latter case. Externalities may arise both on the production and consumption side of the economy. A famous type of production externalities is the category known as 'the tragedy of the commons' (Hardin 1968). If there is common ownership of land, each owner has an incentive to let his cattle graze more than is rational from the viewpoint of the group of owners as a whole. A more modern example is where a manufacturing plant releases emissions into air, soil or water so as to affect negatively the production possibilities or costs of firms in the tourism or fishing industries. This case can be seen as another example of the tragedy of the commons, since the natural recipients can be defined as commons in a more general sense. 2 A central example of consumption externalities is traffic congestion, which arises from the fact that no individual car owner has an incentive to take account of the additional cost imposed on other drivers by his own car use. Thus, externalities may be generated by actions both by producers and consumers, and they may also affect both producers and consumers. A common element of the examples is that the agents who generate the externalities increase the costs or reduce the benefits of other agents. The competitive price mechanism fails to equate marginal social costs and marginal social benefits. Another unifying perspective on these examples is that negative externalities from the consumption or production of private goods reduce the availability of public goods like clean air, clean water or uncongested roads.

It is far from obvious that, having identified potential cases of market failure, economists should proceed to recommend government action for their resolution. In a commons type of situation in which there is a relatively small number of agents, each one of them will have an incentive to negotiate a contract with the other affected parties in order to arrive at an efficient solution; this is the argument developed in the influential paper by Coase (1960). However, as the number of affected agents becomes large, individual incentives to enter into costly negotiations become very weak. A natural outcome in such cases is that the responsibility to arrive at a socially efficient solution comes to rest on some political authority, be it local, national or even global. Even in the context of a large number of agents, however, attempts by the government to improve on the market outcome may not be successful; there are policy failures as well as market failures. Policy recommendations should take into account whether or not government is in fact likely to improve on the performance of an imperfect market.

The inefficiency generated by environmental externalities arises because individual agents do not take account of the effects of their own actions on the welfare of others. Levying a tax on the action in question that reflects the social impact of these harmful effects, leads agents to act as if they take the effects into account. The optimal environmental tax internalizes the externality and restores the efficiency of the market mechanism.

1 It is interesting to note that as late as 1957, George Stigler wrote that after Marshall, it was left for Pigou 'to elaborate, and exaggerate, the importance of this source of disharmonies' (1957). With the increasing awareness of environmental problems over the last few decades, few would now argue that Pigou was guilty of any exaggeration.

2 In addition to its effect on production possibilities, this type of emissions also has negative consequences for consumers through health effects and the degradation of natural beauty. 
How high should optimal environmental taxes be? There are two issues here, one concerning the theoretical principles behind the determination of the taxes and one that concerns the empirical implementation of these principles.

The theoretical principles can briefly be described as follows: If the damage takes the form of deterioration of an environmental public good, the tax should reflect the marginal loss of that deterioration to society as a whole, and that marginal value is the sum of the losses suffered by all agents affected by the externality. In the perfect world of first-best welfare economics, these corrective or Pigouvian taxes are the only indirect taxes that are consistent with an efficient market equilibrium. Any further revenue to finance public expenditure or redistribute incomes should be raised by individualized lumpsum taxes. 3 When, more realistically, distortionary taxes have to be used for revenue purposes, a Pigouvian element should be included in the second-best optimal taxes for the commodities that generate the externalities. In both cases one sees the operation of the principle of targeting; the tax incentive aims to affect the decisions that directly influence the externality and to be as neutral as possible with respect to other decisions. 4

How should one estimate the marginal social loss or damage? Obviously, an estimate that is built up from information about the losses suffered by thousands or millions of individuals is not practicable, and simpler methods have to be employed. The value of the ideal theoretical measure of marginal social damage is mainly to guide one's thoughts in the selection of a practical estimation procedure. Empirical analyses of environmental taxes typically start with some target reduction in the amount of emissions and then ask what level of taxes (or other instruments) is required to achieve the target. For this procedure to be optimal, one must assume that the target reduction has been chosen as a result of a cost-benefit analysis of the benefits and costs of the reduction in emissions.

Although the use of taxes is not the only alternative for policy implementation, they have a number of advantages from an efficiency point of view. Consider the case where the externality is generated through the activities of a large number of individual firms, and where the government's aim is to reduce the aggregate level of these activities. To reduce the activity in question imposes a cost on each individual polluter, and in the interests of production efficiency one would like the total cost of achieving the reduction to be as small as possible. Assuming that the marginal cost is increasing, this is achieved when all polluters have the same marginal cost of pollution reduction, which will be the case when they all face the same tax. If the polluters are consumers instead of firms, the argument has to be modified in terms of expenditure rather than cost, and the effect of the tax is to achieve consumption efficiency rather than production efficiency, but the basic economic insight is the same: the environmental tax can achieve the desired reduction of the activity in question at minimal sacrifice to society as a whole.

3 A simple model of the first-best case is set out in Appendix A.

4 The principles of second-best environmental taxation were discussed in Sandmo (1975); see also Sandmo (2000, ch. 5). 


\section{$3 \quad$ Alternatives to taxes}

The main alternative to taxes is the use of quantitative regulations or quotas. In principle, it is clear that if one wishes to achieve a given reduction of the level of some harmful activity, this can in fact be done either by taxes or quotas, and various versions of a quota system have been widely used in practice. In judging the efficiency aspects of quota systems, one has to distinguish between fixed and transferable quotas.

In principle, any quota system presumes that a quota can be levied on each individual polluter. With a fixed quota, the polluter must limit his emissions to the quota that has been allocated to him; if he exceeds it, he is liable to punishment. The environment can be regarded as a public good that is being 'produced' by the actions of a large number of individual polluters; a reduction of emissions produces more environmental quality. Since efficiency in production implies that the marginal cost of production should be the same for all producers, quotas should be tight for polluters with a low marginal cost of reducing pollution and liberal for high-cost polluters. Imposing individual quotas on polluters according to this principle raises enormous informational problems if the number of polluters is large. In practice, therefore, some simpler rule-like basing quotas on past emissions - has to be found, and this is likely to violate the requirement of production efficiency. 5

An alternative to the fixed quota system is to make quotas transferable between polluters. Someone who finds that it is extremely costly to meet the demands of the quota may buy additional units of quota from another polluter whose cost of reducing emissions is relatively low. Suppose that there is a large number of polluters, and consequently a large volume of quota units being traded. One could then imagine a competitive equilibrium in quotas, where all polluters buy or sell quota units at a uniform price so that the demand for quotas equals the supply. Cost minimization on the part of polluters implies that they will reduce pollution to the point where the marginal cost of reducing pollution is equal to the price of a unit of quota. But this means that the marginal cost of reducing pollution will be the same for all polluters, so that production efficiency is obtained under the system of transferable quotas, just as with a tax on emissions.

In fact, the equivalence between the two systems can be pushed even further. The optimal Pigouvian tax rate on emissions will result in some overall level of pollution. Suppose that one starts with the optimal level of emissions and issues quotas in exactly this amount. Then the equilibrium unit price of quotas will be exactly equal to the Pigouvian tax rate. If initial ownership of the quotas rests with the government, it could sell quotas to private polluters - either through some type of quota exchange system or by auction - and collect the same amount in sales revenue as it would otherwise collect in taxes. Thus, in terms of both production efficiency and in their implications for government revenue, environmental taxes and transferable quotas are equivalent.

In choosing between the two systems, one must rely on considerations that have not been included in the present discussion, and an obvious item that has been left aside is the cost of administration. This includes, first, the cost of the necessary bureaucracy in

5 In Sandmo (2002) I consider the extent to which the expected fine for quota violations can play the same role as an environmental tax in achieving production efficiency, and show that this will be true only in very special cases. 
setting up the systems and running their daily operations. Second, it would include the resources necessary to control environmental tax evasion and quota violations. The relative costs of taxes versus quotas are likely to be specific to the particular type of environmental pollution being considered, so that it is difficult to draw a general conclusion concerning the relative costs of running a tax or quota system. Another consideration that might be important for social and political acceptance has to do with the perceived morality of the two systems. It is not unusual to hear it being said that the government should not be allowed to earn money on socially harmful activities. This viewpoint is based on a complete misunderstanding of the role of incentives, and in any case it is an argument against both taxes and transferable quotas. 6 A more subtle point is that under the tax system, polluters pay for the harmful activities that they have in fact undertaken, whereas under the quota system they buy themselves the right to carry out these activities in the future, and the latter case may possibly be seen as morally more objectionable than the former.

We conclude that a system of transferable quotas is an alternative to the use of environmental taxes that have many of the same properties. If wisely used, it leads individual economic agents to modify their behaviour in a way that causes the market system to function efficiently, even in the presence of external effects. Keeping this result in mind, we now revert to the case of environmental taxes. Are there other gains or 'social dividends' from the use of environmental taxes? So far, we have neglected the possible benefit of the tax revenue that accrues to the government. Could this revenue generate additional dividends for society?

\section{The double dividend issue}

The introduction of environmental taxes creates a new source of tax revenue for the government. Because this happens without any efficiency loss to the economy — at least not in the ideal version of the tax system - the revenue can be seen as a pure transfer between the private and public sector, just like the individualized lumpsum taxes familiar from welfare economics. However, a number of researchers have pointed out that this new source of revenue may in fact create a social gain for the economy over and above its effect on the environment, so it has become customary to speak of 'the double dividend'. The second dividend has been defined in several different ways, but it may be useful to distinguish between three kinds.

First, if one assumes that the level of public expenditure is to be held constant during the process of introducing environmental taxes, this implies that other taxes will have to play a smaller role in the economy, leading to a reduction of other indirect and direct taxes. The reduced role of distortionary taxes in the economy will diminish the overall efficiency loss from taxation, so that this tax efficiency dividend is in addition to the environmental dividend. This is the most fundamental notion of the double dividend.

Second, however, one may question the rationale of assuming constant tax revenue. If the tax system as a whole becomes more efficient, it may not be rational to hold the

6 In fact, it could also be seen as an argument against fixed quotas, since these, to be effective, must obviously specify punishments for quota violations. If punishment takes the form of fines, the government will be getting revenue from pollution activities in this case also. 
level of public expenditure constant. An optimal level of public expenditure should satisfy the condition that the marginal value of the expenditure should be equal to its marginal social cost. The latter has two components: there is the direct resource cost of factor use, and in addition there is the efficiency cost of the taxes used to withdraw the resources from the private sector. With the introduction of environmental taxes, the tax system as a whole becomes more efficient and the efficiency cost goes down. This may justify higher public expenditure, and the justification is obviously stronger, the less efficient the tax system was at the time of introduction of environmental taxes.

Third, much attention has been given to the possibility that a 'green' tax reform might lead to a reduction of unemployment. The idea behind this possibility is that wages, for a variety of possible reasons, are in fact set above the level required for full employment, with actual employment being determined from the demand side of the labour market. An increase of environmental or 'green' taxation in combination with a reduction of the payroll tax would lower labour cost to employers, increase the demand for labour and consequently reduce unemployment (assuming a constant supply of labour).

All the three candidates for the second dividend have been subjected to intensive theoretical research; for recent surveys see Goulder (1995), Bovenberg (1999) and Schöb (2003). The research has demonstrated that any of the three versions of the double dividend hypothesis are indeed possible outcomes of a green tax reform, but that a positive second dividend is by no means assured. Here we can only touch on the reasons for these ambiguities. In the case of the tax efficiency dividend, whether or not it is realized depends on which distortionary taxes are being cut. Suppose, for example, that the tax system discourages labour, but that the proposal for a green tax reform does not involve the reduction of taxes on labour; instead, it is proposed to cut taxes on consumer goods that are in fact complementary with leisure. It is easy to see that this reform could exacerbate the distortion of the labour-leisure choice and increase the overall efficiency loss from the tax system. This could also increase the marginal cost of public funds and thus jeopardize the public expenditure dividend. In the case of the employment dividend, a complicating issue is the incidence effect of the tax changes. It seems unrealistic to believe that a trade union will not try to capture some of the benefits from a reduction of the payroll tax in the form of higher gross wages; in addition, it might demand compensation for the increase of indirect taxes. The result is that there is no guarantee that gross wages will fall and that employment will go up.

To conclude this brief review of the double dividend arguments, there are no guarantees that a green tax reform will also involve a secondary dividend in terms of a more efficient tax system, a lower social cost of public expenditure or a decrease of unemployment. However, this should not be construed to mean that a secondary dividend is not possible. What the literature does point out is that the secondary gain depends on the precise nature of the reform, i.e. on all the components of the proposed tax reform. If the reform is carried out with careful attention to the interaction between taxes and markets, it has the potential to result in a double dividend. Finally, it should be stressed that the empirical magnitude of the dividends will depend not on the magnitudes of the tax rates as such, but on their effects on quantities, as reflected in the elasticities of demand and supply. 


\section{Distributional concerns}

One important objection to the introduction of environmental taxes focuses on the distributional effects. A greater role for environmental taxes means, it is argued, more emphasis on indirect taxes, and consequently a diminished role for the tax system in the redistribution of income. A green tax reform may improve efficiency, but it does so at the cost of redistributing income from the poor to the rich. This is particularly important in the case of energy taxes. Expenditure on energy, particularly for heating and cooking, weighs more heavily in low-income budgets, so that higher energy prices redistribute income in disfavour of the poor. There are several reasons why this view is too simplified, and one needs to consider more carefully exactly how such a reform is carried out.

If one imagines, in line with the first of the three double dividend hypotheses, that an increase of environmental taxation is combined with cuts in the direct taxation of income and wealth, it is a reasonable assumption that the substitution of indirect for direct taxes will involve more inequality of after-tax income. But there is no particular reason why the tax cuts should be carried out with a complete disregard for their distributional impact. A society that cares both about efficiency and equity could let any adverse distributional effects of a green tax reform be compensated by changes in the degree of progressivity of the combined system of direct taxation and income transfers, or it could substitute green taxes for other indirect taxes that have a less egalitarian profile. Some economists would go as far as to argue that environmental taxes should be set with sole regard for their main function, which is to internalize environmental externalities, while there are other policy instruments which are better suited for redistribution of income.

How convincing this argument is obviously depends on how effective the other instruments are in terms of achieving redistributive goals. If a country has a progressive tax system of direct taxation, a well-developed system of social assistance and social security as well as a system of differentiated regional transfers, the distributional argument against environmental taxes is weak. The less the degree to which these assumptions are satisfied, the more important it becomes to strike a balance between efficiency and equity considerations in the design of environmental taxes. 7

However, there is also a need to take a wider view. Suppose that an environmental tax is levied on a consumer good which has harmful environmental effects. This has two distinct effects on the welfare of the consumer. On the one hand he suffers a loss of real income, since the price of one of the goods that he consumes has gone up. On the other hand the tax increases the quality of the environment, which is a gain. In judging the overall distributional impact of the tax, one has to take account of both effects. Even if the consumption of this good were proportional to income so that a price increase had no effects on the distribution of real incomes, the tax increase could still benefit the poor, provided that the environmental impact of the tax were such as to benefit them in particular. Of course the reverse effect is also a possibility; the main point is that both

7 Dinan and Rogers (2002) analyse the related problem of the distributional effects of a system of tradable carbon quotas in the United States. It turns out that the impact of the system across five income groups is crucially dependent of the assumption that they make about offsetting changes in the tax system 
effects have to be taken into account in a serious study of the distributional effects of environmental taxes. 8

\section{Application to developing countries}

The theory of environmental externalities has been developed mainly with a view towards application in industrialized countries. Nevertheless, when one reads the literature on environmental taxation, one may easily get the impression that its policy conclusions make a claim to almost universal validity. There are hardly any explicit discussions of the institutional framework in which the policies are assumed to work, and one has to look behind the formal apparatus in order to discover that there are in fact some implicit assumptions that should make one cautious about applying the conclusions to countries at a different stage of development. An example of such an assumption is that markets work in a way that can at least roughly be described as perfect competition. Another is that the statutory taxes are at least roughly equal to effective taxes, i.e. there is no major problem of avoidance or evasion. Last but not least, it is assumed that a policy of environmental taxation can, to a large extent, be designed without much regard for its distributional impact. The reason for this view is the one mentioned above, viz. that any adverse distributional effects can be neutralized by means of compensating changes in direct taxation. None of these assumptions are completely realistic in industrial countries either, but in the context of developing countries they are much more likely to be seriously misleading. In particular, the assumption that environmental tax design can be completely isolated from redistributive aspects becomes very doubtful in countries where direct taxes are of little importance because of problems with taxpayer literacy and inadequate resources for tax administration.

Another area where the theory of environmental taxation perhaps needs a different emphasis is in the nature of the externalities caused by environmental pollution. In industrialized countries the emphasis has been on the environment as a public consumption good. But as Dasgupta (2001) and others have pointed out, environmental pollution and resource depletion in developing countries are likely to have major effects on the productive economic base of society and so have more direct material consequences for the standard of living of poor people. In fact, environmental degradation not only worsens the material conditions under which poor people live, it also causes poverty through the incentive mechanisms that exist in subsistence agriculture. One example of such a mechanism is where the need to provide cheap fuel for heating and cooking leads poor farmers to cut down the trees on their soil. This may start or speed up a process of soil erosion which makes the conditions for farming worse than they were before. This perspective on the link between the environment and the standard of living is a different one from that which we find in some of the literature, where environmental goods tend to be regarded as luxury consumption goods, something that one can afford once the more important consumer needs have been satisfied.

8 A further complication in the study of distributional effects of energy taxes is that energy is not only a consumption good but also a factor of production. Higher energy prices will lead to higher prices of consumption goods that are produced by energy-intensive technologies, and a full study of tax incidence would have to take account of these general equilibrium effects. 


\section{$7 \quad$ Global externalities}

Many types of environmental externalities are transnational; harmful emissions in one country are carried by land, sea or air to cause damage in other countries. In some cases, like the emission of greenhouse gases that contribute to global warming, all countries are both polluters and victims of pollution. A direct application of standard insights should lead one to recommend taxes on polluters in order that they may internalize the damages that they cause. But there are some difficulties with this solution in an international setting.

The most obvious complication is that there exists at present no international authority to impose taxes and collect revenue. In a single country, the government that makes decisions about tax rates can also provide the resources for tax administration and enforcement. People, who are opposed to a new tax in their own country because they stand to lose by it, will nevertheless be forced to pay it. But in the international community of nations, with a proposal to impose a uniform tax on $\mathrm{CO}_{2}$ emissions, for example, each nation has to agree to the proposal on a voluntary basis. This creates a challenge for tax design which has no direct counterpart in national tax policy.

In spite of this, it is of considerable interest to analyse the problem of optimal tax design from the viewpoint of global welfare maximization. 9 This must not be taken to imply that there is in fact some world authority that can actually implement such a policy, but it is a theoretical approach that leads to a better understanding of the trade-off between efficiency and equity considerations in global tax design. Thus, one issue that can be discussed in this framework is whether such a globally optimal tax should reflect equity consideration. Some proponents of the $\mathrm{CO}_{2}$ tax, which will be discussed in more detail below, claim that it should be designed so as to satisfy the conditions for world production efficiency. Indeed, to ensure that emissions will be reduced the most where the marginal cost is lowest, is claimed to be the main advantage of the tax. The question is whether this will lead to an ethically acceptable distribution of the cost between rich and poor countries. If not, should one design compensatory transfers, or should the design of the environmental taxes themselves have built-in distributional elements?

Suppose for simplicity that the world consists of two countries, one rich and one developing. 10 Consumers in each of the two countries have preferences defined on their own consumption of private goods; in addition, their utility or standard of living is affected by a negative global externality which is caused by total world production of a particular commodity. Each country would have an incentive to impose a tax on the commodity in question, but since it cannot be expected to take account of the damage caused in the rest of the world, there is a strong presumption that the taxes in all countries would be too low compared to the global cooperative optimum.11 Global

9 Although the analysis of this paper relates to optimal tax design, the results are also applicable to the problem of tax reform. The insights that we get from studying, for example, the optimal combination of environmental and other indirect taxes have a direct application to the study of the welfare effects from substituting environmental for other indirect taxes.

10 Appendix B develops a mathematical model of this case.

11 For theoretical analyses of this presumption and the extent of its validity, see Williams (1966) and Boskin (1973). Their discussions are set in the related context of local governments providing public goods with jurisdictional spillovers. 
welfare maximization would imply a tax that is related to the global sum of marginal benefits to world consumers. This is obtained by first computing the sum for all consumers in each of the countries and then summing across countries.

An important question is whether, in assessing the global sum of benefits, the benefits received by consumers in rich and poor countries should receive the same weight. The benefit received by each consumer is his marginal willingness to pay for environmental improvement, and this benefit, assuming that it could be elicited in an empirically reliable manner, would reflect both his preferences and his ability to pay. We may not find it ethically acceptable that the benefit received by a poor African peasant should count for so little in the assessment of the global benefit just because he is so poor, and from an egalitarian perspective it would seem reasonable to give a higher weight to his benefit than to a representative consumer in a rich country. This problem is of special importance in an international context because redistributive taxation and transfers are clearly of much less importance internationally than within any particular country. Appendix B analyses two polar cases of international redistribution. In the first case, there is perfect redistribution in each country, but no international redistribution. In the second case, the assumption of perfect within-country redistribution is preserved, while now perfect international redistribution is also assumed. The analysis then focuses on the characterization of the optimal environmental tax under the two polar assumptions. 12

Should the tax be uniform or differentiated between rich and poor countries? With perfect international transfers and free international trade, the answer is clear: the tax should be uniform. In this case the world - at least in economic terms - is like the single jurisdiction of the original Samuelson (1954) analysis of optimal public goods supply. Then the policy objectives of efficiency and equity can be separated from each other, and in particular we would have production efficiency: the marginal cost of environmental improvement should be the same in rich and poor countries. However, if there are no transfers and the social welfare function is egalitarian, more weight should be placed on the willingness of the citizens in the poor country to pay. In that case, production efficiency is no longer desirable, and the global optimum is a situation where the tax as well as the marginal cost of improving the environment is lower in the developing country. 13 From the viewpoint of world welfare, it is rational to increase the global cost of environmental improvement if by so doing one can ensure that the poor country bears less of the cost burden. When lumpsum transfers are ruled out, we are in the world of the second best where redistributive concerns may have to be reflected in the design of the system of commodity taxes.

12 Both of the two polar cases are obviously unrealistic. National redistribution is not perfect and nondistortionary, and international redistribution, while it does occur, is far from the lumpsum ideal of welfare economics. But the study of polar cases has a long history in economics. In international economics, in particular, there is a long tradition for studying the contrast between autarky and perfectly free trade, none of which are realistic descriptions of actual economies. Another polar case assumption in international economics of the Heckscher-Ohlin variety is that factors of production are perfectly mobile within the national economies, but completely immobile internationally.

13 In the limit, as the relative weight put on the consumption of people in the poor country becomes very large, the whole burden of reducing global pollution should fall on the rich country, and the tax on the poor country should be zero. This case could be seen as an application of Rawls' difference principle to the problem of international redistribution. However, Rawls (1999) warns against a simple-minded application of the principle to international relations. 
Which of the two polar assumptions is the more realistic one? Anyone who observes the extent of world income inequality and the amount of international transfers will have difficulties with concluding that his observations can be interpreted as the outcome of global welfare maximization; the case without international transfers is therefore the one that comes closest to reality. To implement such a scheme is, however, far from simple. A major difficulty is that in the real world of many countries, there is no simple division of countries into the 'developing' and 'rich' categories, and a system by which every country pays the tax at a different rate raises major political and administrative difficulties. The problem is even more complicated if one envisages several global pollutants with associated tax rates, where for each tax rate one needs to strike a balance between cost efficiency and distributional equity.

The approach to tax design via global welfare optimization leaves open the question of its institutional and political foundation. Clearly, such a tax will have to be based on some kind of international agreement, possibly in combination with the creation of a world tax authority. To ensure voluntary participation by all countries, the tax would have to be designed in such a way that all countries gain by it. All countries will gain from a better global environment, but since both the gains and the tax payments are likely to be unevenly distributed between countries, it is not clear that the net gain - the environmental gain minus taxes paid - will be positive for all countries. But the income received by the world tax authority could be redistributed to the participating countries so that net gains are assured for all participants; the redistribution scheme could also be designed such that the poor countries would gain more than the rich. These issues are considered further below.

\section{Tax design and political acceptability}

What are the prospects for establishing a system of global environmental taxation? We have seen that a strong case can be established for such a system on the basis of welfare economics, but what are the prospects for its implementation? With regard to the case of greenhouse gas emissions, James Poterba no doubt expresses a common view among economists when he writes

....while efficiency considerations create a presumption for using coordinated international policies to alter greenhouse gas emissions, the prospects for such action are bleak (Poterba 1993: 48).

There are two main reasons for the pessimistic view. One is that actions taken to prevent or slow down global warming involve the certainty of present costs against the uncertainty of future benefits. The uncertainty element comes in because of our incomplete knowledge concerning the effects of greenhouse gas emissions on the global climate in the future. The time element is also of major importance in judging the probability of political enactment. The time perspective in global warming is so long that even with moderate rates of time discounting, the costs will easily come to dominate the benefits. This particular ground for pessimism, it should be stressed, applies both to a single country and to the world community.

The second reason for pessimism is the fact that an efficient tax policy for global environmental improvement presupposes coordinated action among countries, but with 
each country knowing that the main beneficiaries from its own actions will be other countries. This creates an incentive for each country to be a free rider on the policies of the others, leading to a political equilibrium where all countries believe that inadequate action is taken, but where all feel powerless to break out of the low tax equilibrium trap. It would seem fruitful, therefore, to try to search for arguments that would increase the probability of political adoption of global environmental taxes.

One such argument would be that of the double dividend. From a domestic point of view, increasing the tax on fossil fuels would not only correct a market failure, it would also enable the national government to cut other taxes or to expand public expenditure at a lower efficiency cost. Note, however, that this argument provides no answer to the pessimism stemming from the long time-horizon and the free rider problem.

Another approach would be to introduce global environmental taxes in conjunction with a commitment to use the revenue for a specific purpose, as in the current proposal to use it for promoting economic development. The emission of greenhouse gases contributes to a deterioration of the quality of the atmosphere, the most global of all commons. Taxes on emissions could then be seen as charges for use of the common property, to be redistributed to the owners - all the world's countries - on the basis of some criterion of distributive justice. Exactly what that criterion should be, would be a matter for deliberation between the parties to the treaty, but it would clearly have to favour the developing world, while the rich countries would pay the larger share of the taxes. In coupling proposals of new taxes to improve the global efficiency of resource allocation and redistributing income in favour of the poor, the approach might stand a better chance of political acceptance than either of the two proposals would be likely to muster on their own.

Is such a scheme likely to attract the support of the rich countries? The presumption is that a slow-down of global warming would be a benefit to all;14 at the same time, however, there would be a net transfer of tax revenue from the rich to the developing countries. On a narrow calculation of national self-interest, some rich countries might find the proposal unattractive. However, wider considerations of the fairness involved in charging for the use of the global commons as well as the attainment of a more equitable distribution of world income might still appeal to an extended notion of the national self-interest. 15

There are several alternatives regarding the construction of a system of global environmental taxation that combines efficiency and equity considerations. From the previous discussion two main alternatives emerge:

14 Cooper (1998) and Poterba (1993) cite evidence that countries like Canada and Russia might profit from global warming mainly because of higher agricultural yields. This might seem a narrow concept of the national interest, but in any case the possibility that a few countries could come to gain from global warming is not a crucial argument against the scheme.

15 Newbery (1990) and Mäler (1991) analyse cost-efficient reduction of sulphur emissions in a European context and identify the countries that gain or lose by an efficient policy. Mäler also develops a system for revenue distribution that makes all countries that participate in the policy into net beneficiaries by the arrangement. Something similar could clearly be worked out on a global scale, which would imply that the rich countries would also get a share of the tax revenue. 
A) A uniform tax designed to promote production efficiency combined with a separate system for equity-based distribution of the tax revenue;

B) A non-uniform tax with rates depending on the income level of the taxcollecting country.

In addition, a simplified case of $\mathrm{B}$ ) would be:

C) A positive efficiency-based rate of tax on the rich countries combined with a zero tax on developing countries.

An important issue of system design is that a politically acceptable treaty needs to be based to the largest extent possible on criteria that are capable of empirical verification and are easy to understand. None of the three alternatives satisfy this requirement completely; this is unavoidable because they all involve an element of redistribution, which clearly must be based on value judgements. My own view is that alternative $A$ is better than $\mathrm{B}$ and $\mathrm{C}$ on this score. The basic issues involved are the same, but $\mathrm{A}$ has a separation of efficiency and equity considerations which implies that the tax rate and the redistribution system could more easily be negotiated separately than in the other two cases. The ranking of alternatives $\mathrm{B}$ and $\mathrm{C}$ is more difficult. 16 Alternative $\mathrm{C}$ has much to recommend it in the way of simplicity. On the other hand, the redistributive element is weaker than in B, since countries are simply divided into two groups with no withingroup redistribution. Having just two tax rates instead of the several rates required by alternative B may be an advantage from an administrative and political point of view; on the other hand, setting the dividing line (presumably in terms of per capita income) between the two groups becomes significant, imposing a high marginal tax on the country which makes the transition from developing to 'rich' 17 Perhaps the simplicity of alternative $\mathrm{C}$ should be decisive in ranking it ahead of $\mathrm{B}$.

It needs to be kept in mind that countries at present have widely different effective rates of tax on the emission of greenhouse gases; even within each country there will be a variety of effective rates, depending on the source of emissions. If countries were to impose a new uniform tax on themselves, effective tax rates would not be equal. It is the effective post-reform rate of tax which, according to alternative A, should be equalized across countries, and this means that allowance must be made for pre-existing taxes. Effective rates of tax should then be equalized within each country, and the single effective rate should be brought in line with the international rate. In all probability this would lead to an increase of the overall rate of tax in a global perspective, but it is also likely that some rates in some countries would have to be cut in order to achieve global uniformity. This argument obviously has to be modified if one were to adopt any one of the tax systems B or C instead of A, but there would still be a strong case for a uniform rate of tax within each rich country and between the group of rich countries.

16 The analysis of Appendix B does not provide much help in this ranking, since it assumes just two countries, and the difference between alternatives $\mathrm{B}$ and $\mathrm{C}$ becomes really significant when there are several countries.

17 However, even a developing country not obliged to pay any tax under the treaty could find it in its own interest to levy such taxes for the purely domestic interest in reaping one or more of the second dividends discussed above. 
The argument in favour of environmental taxes is that they change the incentives of the individual economic agents whose actions are the causes of the externalities. A treaty between countries which merely obliges the individual country to pay taxes in proportion to its emissions leaves open the question of how the country passes this obligation on to its citizens; see the more detailed discussion of 'fiscal architecture' in Atkinson (2003b). If the government in question decides to finance this tax payment out of its general tax revenue, the individual incentives would not be such as to promote domestic or global efficiency. On the other hand, the domestic government clearly has an interest in designing a tax system with the right incentives; giving firms and consumers incentives to cut back on emissions would at the same time diminish the government's tax obligations under the treaty. This issue is discussed in more detail in the study by Boadway (2003).

As regards the institutional framework for collecting the tax and spending the revenue, several arrangements might be considered, and the detailed institutional framework would obviously have to be considered later. Nevertheless, a few general remarks are in order. Taxes in each individual country, for example, on the use of fossil fuels, would have to be collected by the domestic government and paid by it to an international agency. Whether this should be a new and separate institution or whether the taxcollecting task could be incorporated in an existing institution, is difficult to say. There are presumably cost advantages to not having to build a new international agency from the ground. However, if the agency is put in charge of collecting revenue from a number of different sources (global environmental taxes, the Tobin tax, a global lottery, etc.) there is more to be said for establishing it as a separate institution. One also needs to consider the next step of channelling the revenue into development finance. The agency would need to develop a system for passing the revenue on to institutions that are actually in charge of allocating resources to development projects. A crucial question is then whether the transfer of funds should take place according to some fixed rule or whether the agency itself should develop priorities among projects and receiving institutions. This should probably be among the first issues to be discussed among the parties to international treaties about the various new sources of development funding.

\section{Revenue potential of environmental taxes}

There are a number of activities that give rise to external effects that cross borders and could be said to be harmful to the global environment. However, at least for the purpose of the present discussion, it will be useful to limit discussion to the types of pollution that most directly affect the global commons, viz. the emission of greenhouse gases, in particular a tax on carbon $\left(\mathrm{CO}_{2}\right)$ emissions. What is the revenue potential of such taxes? How important could they be in providing additional funds for development finance?

The answer seems to be that they could be very important, but that there are a number of uncertainties attached to the estimation of their revenue potential. The World Development Report 1999/2000 estimates world emissions of carbon dioxide at 22,754 million metric tons in 1996 (World Bank 2000: 249), equivalent at a conversion factor of 3.67 to 6.2 billion metric tons of carbon. Clunies-Ross (2003) points out that a uniform tax on carbon use at a rate of US\$21 per metric ton of carbon (equivalent to a 
gasoline tax of 4.8 cents per US gallon or roughly 0.01 EUR per litre) 18 would yield annual revenue of about US\$130 billion per year. This assumes that the tax is levied at a uniform rate on all countries. If instead it is assumed that it is levied only on those countries that according to the World Bank are classified as 'high income', having a per capita income of at least US\$9,361 in 1996, the figure drops to about US\$61 billion per year. When these figures are compared to estimates of the additional resources required to reach the Millennium Development Goals by 2015, which are in the range of US\$30-70 billion per year (Atkinson 2003a), it is clear that the revenue potential is indeed very large, even for such a modest rate of tax. Cooper (1998) cites an OECD study that estimates the revenue from a carbon tax on a lower taxbase (5.2 billion metric tons) at US\$750 billion per year. This is almost six times the amount suggested by Clunies-Ross, being based on a tax rate of approximately US\$150 per metric ton (the equivalent of approximately 35 cents per US gallon or 0.08 EUR per litre. 19 Both this and the more modest Clunies-Ross revenue estimates are very high. Thus, even the latter would amount to about 2.5 times the current level of official development assistance in the case of a worldwide tax, and to 1.2 times the level of ODA if only high-income countries are included. The significance of the estimates lies of course not in the precise numbers, but in the indications they give of the order of magnitude involved.

There are both economic and political reasons why these estimates might be too high. One is that the calculations assume that carbon use is unaffected by the tax, presumably because of an assumption that the demand price elasticity is very low. The assumption of a zero price elasticity is of course somewhat paradoxical, because it means that the tax has in fact no effect on $\mathrm{CO}_{2}$ emissions and that there is no environmental benefit from it. Although the assumption appears to be consistent with experiences of short-run fluctuations in, for example, gasoline prices, it is clearly the more long-run elasticities that are relevant in this context. These are likely to be negative, which must lead to a downward adjustment of the taxbase. There seems to be a consensus that although short-run elasticities might well be close to zero, long-run elasticities are more likely to be in the neighbourhood of -0.5 to -1.5 (Pindyck 1979). For illustrative purposes, let us assume that the relevant long-run elasticity is -1 . The Clunies-Ross proposal of a tax equivalent to 0.01 EUR per litre of gasoline implies a price increase (assuming the producer price to be constant at about 1.00 EUR) of roughly one per cent, which would lead to a one per cent reduction of the taxbase. Thus, his revenue estimates would have to be reduced downwards by about one per cent, clearly a very insignificant revision of the original calculations.

It should be kept in mind, however, that the rate of tax envisaged by Clunies-Ross is very low compared to those suggested in the literature on global warming. For example, Cooper (1998) and Poterba (1991) suggest that in order to achieve a significant reduction of emissions, a tax in the range of US\$100-120 per metric ton would be necessary. Whalley and Wiggle (1991) estimate that a tax of about US\$450 - more than twenty times the level assumed by Clunies-Ross - is needed to reduce carbon use by 50 per cent. With a tax rate of this magnitude, the calculation of revenue on the basis of a constant taxbase is apt to be more misleading. The size of the taxbase will in fact have

18 For comparison, this is about one-tenth of the current Norwegian carbon tax.

19 This is approximately 60 per cent of the current carbon component of the Norwegian gasoline tax and less than 10 per cent of the total gasoline tax. 
to adjusted downwards by a percentage equal to the product of the tax rate and the price elasticity. To illustrate, take again the Clunies-Ross case of 6.2 million metric tons as the initial taxbase. With an elasticity of -1 and a tax rate of 20 per cent, the taxbase must be reduced by a factor of 20 per cent. However, with the higher tax rate, the tax revenue is still higher than with the lower tax rate; in fact, with an elasticity of -1 revenue is increasing for all tax rates up to one hundred per cent. 20

The role of the price elasticity of carbon use is worth emphasizing. If policymakers want to use the tax in order to reach both a target level of emissions and a revenue target, achieving the emissions target requires a lower tax, the more elastic the taxbase is. On the other hand, a high elasticity means that a higher tax is needed to meet the revenue target. If the elasticity is in fact quite low, it is therefore likely that a carbon tax, which is decided with the objective of raising certain revenue for development purposes, is likely to be lower than that required to meet environmental objectives.

In spite of the uncertainty that is attached to the magnitude of the relevant elasticities, there can be no doubt that the revenue potential of a global carbon tax is very high. A modest rate of tax, whether levelled globally or only on the rich countries' emissions, would likely raise huge revenues that could potentially be channelled into economic development. But one needs to keep in mind that the estimate of the revenue potential of the carbon tax might not reflect a corresponding increase in tax revenue available for development assistance. Adoption of the global carbon tax would imply a large increase in the outflow of resources for development purposes, and the political system could well react to this by cutting back the amount of ODA over time, or increasing it by less than they would have done, had the global carbon tax not been in place.

\section{Concluding remarks}

The economic case for global environmental taxes, primarily to control the climate externalities that are of increasing concern to public opinion, is very strong. Since these taxes can be seen as charges for use of the global commons, there is also a strong moral case for earmarking the revenue for global development purposes. There is at present wide-spread pessimism concerning the political realism of introducing such taxes; however, earmarking the revenue for development purposes might in fact enhance their political acceptability. The revenue potential of this type of tax appears to be large. A global carbon tax even at modest rates could alone generate sufficient revenue to finance the Millennium Development Goals, and with a higher tax rate-one that is designed to achieve a substantial environmental improvement - the potential could be increased even further.

If such a system of taxes were to become enacted, one would clearly be justified in speaking of an international double dividend. First, there would be an improvement of the global environment. Second, there would be an increased flow of resources into economic development, and at a lower marginal source of public funds than is the case

20 If $t$ is the tax rate and $x$ is the taxbase, revenue is $R=t x$. The effect of a tax increase on revenue, assuming the producer price to be constant, can be written as $\partial R / \partial t=x(1+\theta \varepsilon)$, where $\theta$ is the tax rate in percentage terms and $\varepsilon$ is the price elasticity of demand. For the special case where $\varepsilon=-1$, we accordingly have that $\partial R / \partial t=x(1-\theta)$. 
for most other taxes currently being used to fund development aid. Whether this argument is persuasive enough to overcome the free rider problems inherent in all issues involving global public goods and externalities, remains to be seen. 


\section{Appendix A}

\section{A formal model of environmental taxation: The single country case ${ }^{21}$}

It will be useful to establish a theoretical frame of reference in the form of a simple model for a single country. It has a number of consumers, indexed by $i(i=1, \ldots ., n)$, with utility functions that depend on the quantity consumed of two commodities, indexed 0 and 1 , as well as on the amount of environmental pollution, $e$ :

$$
u^{i}=u^{i}\left(x_{0}^{i}, x_{1}^{i}, e\right)
$$

The utility functions are increasing in the first two arguments and decreasing in the third. Let total production of the two goods be $y_{0}$ and $y_{l}$, respectively, so that

$$
\Sigma_{i} x_{0}^{i}=y_{0} \text { and } \Sigma_{i} x_{1}^{i}=y_{1} \text {. }
$$

The amount of environmental pollution is an increasing function of the output of commodity 1 , so that without loss of generality 22 we may simply write

$$
e=y_{1} \text {. }
$$

Industry 1 is cast in the role of the 'dirty industry', but the pollution technology is of course a drastic simplification of real-life situations, where pollution is likely to depend on the specific technology used in production. It would not be conceptually difficult to take account of this, but it makes the analysis less transparent and does not add much in the way of interesting economic insights.

We assume that there is an aggregate production constraint for the economy as a whole, which has the quasi-linear form

$$
y_{0}+C\left(y_{1}\right)-\omega=0, C(0)=0, C^{\prime}\left(y_{1}\right)>0, C^{\prime \prime}\left(y_{1}\right)>0 .
$$

We now characterize the optimal allocation of resources in this economy as the maximum of a Bergson-Samuelson social welfare function

$$
W=W\left(u^{1}, \ldots ., u^{n}\right) .
$$

Letting subscripts denote partial derivatives, it is easy to show that the optimum can be characterized by the conditions

$$
\left(u^{h}{ }_{1} / u_{0}^{h}\right)+\sum_{i}\left(u_{e}^{i} / u_{0}^{i}\right)=C_{1}\left(y_{1}\right) . \quad(h=1, \ldots, n)
$$

21 The analysis in this and the following appendix is a further development of the model in Sandmo (2003).

22 The unit function could be replaced by any increasing function without affecting the conclusions of the analysis. 
The first term on the left is the private marginal benefit to consumer $h$ of an additional unit of commodity 1 . The second term, which is negative, is the marginal social damage of increased pollution. This affects all $n$ consumers - including consumer $h$ himself-in a negative way. The condition implies, first, that at the optimum the private marginal benefit of consumption should be the same for all consumers, and, second, that the private marginal benefit adjusted for the marginal social damage, should be equal to the marginal cost of production.

Let us now confront this optimality condition with a competitive equilibrium in which consumers and producers face prices $P$ and $p$, respectively, using commodity 0 as the numéraire. Utility-maximizing consumers, who take the level of environmental pollution as given, 23 will equate their marginal willingness to pay (their marginal rate of substitution) to the consumer price. Profit-maximizing firms will set marginal cost equal to the producer price, so that competitive equilibrium will be characterized by the conditions

$$
\begin{aligned}
& u_{1}^{h} / u_{0}^{h}=P, \quad(h=1, \ldots, n) \\
& C_{1}\left(y_{1}\right)=p
\end{aligned}
$$

One sees immediately that the equilibrium will satisfy the optimality condition (6) only if a tax wedge is driven between the consumer and producer price, so that

$$
P-t=p \text { and } t=-\Sigma_{i}\left(u_{e}^{i} / u_{0}^{i}\right) .
$$

The optimal environmental tax is the aggregate marginal willingness to pay for environmental improvement. It is of course no coincidence that the tax formula is reminiscent of the Samuelson (1954) condition for the optimal supply of public goods, for the effect of the tax discouragement of consumption is precisely to improve the quality of the environment as a public good.

This is a very simple model in a number of respects. Most importantly, it assumesrather implicitly, as presented here-that lumpsum redistribution between consumers is possible, so that the environmental tax can be set without any regard for distributional effects. 24 Moreover, it presents a very aggregate view of the production side of the economy. However, we shall use the formulation as a building block for the construction of a model of global externalities and environmental taxes, in which these complications will in fact be moved to the forefront of the analysis. From this perspective, it is useful to keep the single country case as simple as possible.

23 This is equivalent to taking the total output of the dirty commodity as given and is just the standard competitive assumption.

24 Formally, one set of first order conditions requires that the marginal contribution to social welfare of the consumption of the numéraire good is the same for all consumers. 


\section{Appendix B}

\section{Extensions to a two-country model}

To make matters simple, we assume that the world consists of just two countries, one rich and one developing country. The model does not attempt to explain why one country is rich and one poor; this could be either because of differences in productive resources or because of differences in the technology of production. The environmental externality in question is global in nature, being a global 'bad' for all consumers in the two countries.

Country-specific variables are distinguished by superscripts $D$ and $R$, so that the utility functions of consumers are written as

$$
\begin{aligned}
& u^{i D}=u^{i D}\left(x_{0}^{i D}, x_{1}^{i D}, e\right) \quad(i=1, \ldots, n) \\
& u^{j R}=u^{j R}\left(x_{0}^{j R}, x_{1}^{j R}, e\right) . \quad(j=1, \ldots ., m)
\end{aligned}
$$

The materials balance equations (2) become

$$
\begin{aligned}
& \sum_{i} x^{i D}{ }_{0}=y^{D}{ }_{0} \text { and } \Sigma_{i} x^{i D}{ }_{1}=y^{D}{ }_{1} . \\
& \sum_{j} x^{j R}{ }_{0}=y_{0}^{R} \text { and } \sum_{j} x^{j R}{ }_{1}=y_{1}^{R} .
\end{aligned}
$$

For each commodity, domestic consumption should be equal to domestic production. Note that there are no other constraints on individuals' consumption than aggregate output in the domestic economy. This is equivalent to assuming lumpsum redistribution between individual consumers in each country; however, it is also assumed that there is no redistribution between countries. This is clearly not realistic. Domestic redistribution has in fact to rely on second best instruments like income and commodity taxes while on the other hand there exists a significant amount of international redistribution. The assumption must be seen as a simplified representation of the fact that redistribution in most countries is carried out on a scale far exceeding anything that exists for the world community as a whole, and with a set of instruments that, if far from perfect, are much more targeted on transferring resources from the rich to the poor.

Environmental pollution is assumed to be global in nature and to depend on the sum of the outputs in industry 1 in the two countries, so that

$$
e=y_{1}^{D}+y_{1}^{R} \text {. }
$$

The production constraints of the two countries may differ both with respect to the availability of resources and alternative costs; in other words, production possibility curves may vary both with respect to location and slope:

$$
y_{0}^{D}+C^{D}\left(y^{D}\right)-\omega^{D}=0,
$$




$$
y_{0}^{R}+C^{R}\left(y_{1}^{R}\right)-\omega^{R}=0 .
$$

We now wish to study the implications of global welfare maximization. The global social welfare function is

$$
W=W\left(u^{1 D}, \ldots ., u^{n D} ; u^{1 R}, \ldots, u^{m R}\right) .
$$

Before turning to the formal analysis, it is useful to think about the questions that the analysis of this model can help us to clarify. An interesting question is whether it is desirable to have world production efficiency. Since equation (12) shows the amount of international pollution to be a function of the sum of output from the dirty industries of the two countries, a natural feature of the optimum would be equality of the marginal costs of reducing pollution. Another issue is to what extent distributional weights on the two countries' preferences should be taken into account in the design of the optimal policy. These two issues turn out, in fact, to be closely related.

Consider first the condition for global production efficiency. The problem can be formulated as the maximization of the output of commodity 0 , subject to the condition that the output of commodity 1 is equal to some constant level, so that $y^{D}{ }_{1}+y^{R}{ }_{1}=y^{*}$. Using equations (13a-b), we can write the maximization problem as

$$
\max \left(y_{0}^{D}+y_{0}^{R}\right)=\omega^{D}+\omega^{R}-C^{D}\left(y_{1}^{D}\right)-C^{R}\left(y^{*}-y_{1}^{D}\right) .
$$

Setting the derivative of this expression with respect to $y_{1}^{D}$ equal to zero, we obtain the condition for global production efficiency:

$$
C^{D}{ }_{1}\left(y^{D}{ }_{1}\right)=C^{R}{ }_{1}\left(y^{R}{ }_{1}\right) \text {. }
$$

The marginal cost of producing the dirty good, which is the same as the marginal cost of reducing pollution, should be the same in both countries.

The more general welfare problem is to maximize the social welfare function (14), subject to the four materials balance equations (11a-b) and the two production constraints (13a-b). We skip the details of the derivation and move directly to the two conditions corresponding to (6) for the single country case. For the developing country we have that

$$
\left(u^{h D}{ }_{1} / u^{h D}{ }_{0}\right)+\left[\sum_{i}\left(u^{i D} e^{i D} u_{0}\right)+\sum_{j}\left(u^{j R} e^{\prime} u^{j R}{ }_{0}\right)\left(\lambda^{R} / \lambda^{D}\right)\right]=C^{D}{ }_{1}\left(y^{D}{ }_{1}\right) . \quad(h=1, \ldots, n)
$$

The expression in square brackets is now the marginal global damage from the production of the dirty good. It has two terms, the first being the damage caused in the poor country while the second term is the damage to the rich country, multiplied by the term $\lambda^{R} / \lambda^{D}$. This term is the ratio of the social marginal utilities of income in the two countries; these are equal between individuals within each of the countries because of the assumption of domestic lumpsum redistribution. The social marginal utility of income is actually the marginal contribution to welfare of increasing an individual's consumption of the numéraire commodity 0 , i.e.

$$
\lambda^{D}=W_{i} u^{i D}{ }_{0} \text { and } \lambda^{R}=W_{j} u^{i R}{ }_{0 .}(i=1, \ldots ., n ; j=1, \ldots ., m)
$$


We assume that the global welfare function is egalitarian, which implies the relative welfare weight $\lambda^{R} / \lambda^{D}$ will be less than one. This means that the weight accorded to the marginal social damage for the rich country consumers will be less than that of the consumers in the developing country. Let $P^{D}$ and $p^{D}$ be the consumer and producer prices in the developing country, with the tax rate being $t^{D}=P^{D}-p^{D}$. From (16) and the competitive assumption (see equations (7) and (8)) we may then conclude that the optimal tax in the developing country is

$$
t^{D}=\left[\Sigma_{i}\left(u_{e}^{i D} / u_{0}^{i D}\right)+\Sigma_{j}\left(u_{e}^{j R} e^{j R}\right)\left(\lambda^{R} / \lambda^{D}\right)\right] .
$$

How does this correspond to the optimal tax rate in the rich country? This turns out to satisfy the following condition:

$$
\left(u^{k R}{ }_{1} / u^{k R}{ }_{0}\right)\left(\lambda^{R} / \lambda^{D}\right)+\left[\Sigma_{i}\left(u^{i D} e^{\prime} u^{i D}{ }_{0}\right)+\Sigma_{j}\left(u^{j R} e_{e} u^{j R}{ }_{0}\right)\left(\lambda^{R} / \lambda^{D}\right)\right]=C^{R}{ }_{1}\left(y^{R}{ }_{1}\right)\left(\lambda^{R} / \lambda^{D}\right) .(k=1, \ldots, m)
$$

Let $P^{R}$ and $p^{R}$ be the prices in the rich country and the tax rate the difference between the two. Then we can write the optimal tax rate in the rich country as

$$
t^{R}=\left[\Sigma_{i}\left(u_{e}^{i D} / u_{0}^{i D}\right)\right)\left(\lambda^{D} / \lambda^{R}\right)+\Sigma_{j}\left(u^{j R} e^{j R} u_{0}\right] .
$$

Comparing (20) with (18), we see immediately that

$$
t^{D}=t^{R}\left(\lambda^{R} / \lambda^{D}\right)
$$

Since the relative welfare weight is less than one, this implies that $t^{D}<t^{R}$. At the optimum the optimal tax in the developing country is lower than in the rich country. We may think of the ratio of welfare weights as expressing the degree of egalitarianism embedded in the global social welfare function. In the limit, as the ratio $\lambda^{R} / \lambda^{D}$ approaches zero, giving all weight to the welfare of the developing country, the tax in the developing country goes to zero, and the whole burden of discouraging global pollution falls on tax policy of the rich country.

What about global production efficiency? Using the competitive equilibrium conditions (7) and (8), we can rewrite (21) as

$$
P^{D}-C^{D}{ }_{1}=\left(\lambda^{R} / \lambda^{D}\right)\left(P^{R}-C^{R}{ }_{1}\right)
$$

We cannot conclude from the lower tax rate in the developing country that the marginal cost of reducing pollution should be higher in the developing country. However, in the important special case in which international trade causes equality of commodity prices, so that $P^{D}=P^{R}$, we can indeed conclude that at the optimum

$$
C^{D}{ }_{1}>C^{R}{ }_{1}
$$

The reasons for the difference between the first-best optimal tax rates and the desirability of global production inefficiency are clearly distributional. Both countries contribute to a cleaner global environment by discouraging the production and 
consumption of the dirty good, but the poorer country contributes less. Only in the case where the marginal utilities of income are the same in the two countries, so that $\left(\lambda^{R} / \lambda^{D}\right)=1$, will there be a globally uniform tax rate. In the model, this will be the case if the first part of the materials balance equations (11) is replaced by 25

$$
\sum_{i} x^{i D}+\sum_{j} x^{j R}{ }_{0}=y_{0}^{D}+y_{0}^{R}
$$

which says simply that world consumption must equal world production of the numéraire commodity. With this formulation, the only constraint on the consumption of each country is the aggregate production of commodity 0 in the world as a whole; domestic production is no longer a limit on domestic consumption. Clearly, this is equivalent to assuming lumpsum transfers between the two countries, since the only way in which a country can consume more than its domestic output (without paying for it in the form of international trade) is through transfers from other countries. With this assumption there is no longer any egalitarian case for differentiating the tax rates, since any adverse distributional effect of the environmental tax is compensated by the transfers.

Will this assumption also imply world production efficiency? As condition (22) makes clear this is not necessarily the case, since in equilibrium we have equality between marginal cost and the producer price. Equality of producer prices between countries will only result, except by coincidence, through free international trade. Thus, it is the twin assumptions of lumpsum international transfers and free trade that make the global community into one integrated economy, just like the single country of Appendix A. In this perfectly competitive global economy with no constraints on tax and transfer policies, there is perfect separation of efficiency and equity issues of economic policy, and environmental policy should accordingly be based solely on efficiency considerations. 26

25 Equation (24) should not be confused with a balance of payments equation, which is a constraint on values, not quantities. Both versions of the model, with or without international transfers, are consistent with the presence of international trade; see Sandmo (2003). Without trade, producer prices will differ between countries; with trade, they will be the same.

26 Chichilnisky and Heal (1994) discuss the problem of international production efficiency in a multicountry model with a similar structure to the one used here, but they do not discuss the tax implications. Keen and Wildasin (2003) and Edwards (2002) discuss the desirability of world production efficiency in more general settings, including second best situations where domestic tax systems are distortionary, an obviously important set of cases that is neglected in the present analysis. 


\section{References}

Atkinson, A. B. (2003a). 'Innovative Sources for Development Finance'. Paper prepared for the UNU-WIDER-UN-DESA project on Innovative Sources for Development Finance. Oxford: Nuffield College and Helsinki: UNU-WIDER.

Atkinson, A. B. (2003b). 'Innovative Sources for Development Finance: Over-Arching Issues'. WIDER Disucssion Paper DP2003/88. Helsinki: UNU-WIDER.

Boadway, R. (2003). 'National Taxation, Fiscal Federalism and Global Taxation'. WIDER Discussion Paper DP2003/87. Helsinki: UNU-WIDER.

Boskin, M. J. (1973). 'Local Government Tax and Product Competition and the Optimal Provision of Public Goods'. Journal of Political Economy, 81: 203-10.

Bovenberg, A. L. (1999). 'Green Tax Reforms and the Double Dividend: An Updated Reader's Guide'. International Tax and Public Finance, 6: 421-43.

Chichilnisky, G., and G. Heal (1994). 'Who Should Abate Carbon Emissions?'. Economics Letters, 44: 443-9.

Clunies-Ross, A. (1999). 'Sustaining Revenue for Social Purposes in the Face of Globalization'. Experts Discuss Some Critical Social Development Issues. New York: UNDP-DESA.

Clunies-Ross, A. (2003). 'Resources for Social Development'. Paper prepared for the World Commission on the Social Dimensions of Globalization.

Coase, R. H. (1960). 'The Problem of Social Cost'. Journal of Law and Economics, 3: $1-44$.

Cooper, R. A. (1998). 'Toward a Real Global Warming Treaty'. Foreign Affairs, 77 (2): 66-79.

Dasgupta, P. (2001). Human Well-Being and the Natural Environment. Oxford: Oxford University Press.

Dinan, T., and D. L. Rogers (2002). 'Distributional Effects of Carbon Allowance Trading: How Government Decisions Determine Winners and Losers'. National Tax Journal, 55: 199-221.

Edwards, J. (2002). 'Global Production Efficiency and Pareto-efficient International Taxation. Cambridge: University of Cambridge. Mimeo.

Goulder, L. (1995). 'Environmental Taxation and the Double Dividend: A Reader's Guide'. International Tax and Public Finance, 2: 157-83.

Hardin, G. (1968). 'The Tragedy of the Commons'. Science, 162: 1243-8.

Keen, M., and D. Wildasin (2003). 'Pareto Efficient International Taxation'. (Forthcoming in American Economic Review).

Mäler, K.-G. (1991). 'Environmental Issues in the New Europe', in A. B. Atkinson and R. Brunetta (eds), Economics for the New Europe. London: Macmillan, in association with the International Economic Association, 262-87.

Newbery, D. M. G. (1990). ‘Acid Rain’. Economic Policy, 11: 297-346. 
Pigou, A. C. (1920). The Economics of Welfare, $4^{\text {th }}$ Edition 1932. London: Macmillan.

Pindyck, R. S. (1979). 'Interfuel Substitution and the Industrial Demand for Energy: An International Comparison'. Review of Economics and Statistics, 61: 169-79.

Poterba, J. M. (1991). 'Tax Policy to Combat Global Warming: On Designing a Carbon Tax', in R. Dornbusch and J. M. Poterba (eds), Global Warming: Economic Policy Responses. Cambridge, MA: MIT Press.

Poterba, J. M. (1993). 'Global Warming Policy: A Public Finance Perspective'. Journal of Economic Perspectives, 7 (4): 47-63.

Rawls, J. (1999). The Law of Peoples. Cambridge, MA: Harvard University Press.

Samuelson, P. A. (1954). 'The Pure Theory of Public Expenditure'. Review of Economics and Statistics, 36: 387-9.

Sandmo, A. (1975). 'Optimal Taxation in the Presence of Externalities'. Swedish Journal of Economics, 77: 86-98. Reprinted in L. H. Goulder (2002) (ed.), Environmental Policy Making in Economies with Prior Tax Distortions. Cheltenham: Edward Elgar.

Sandmo, A. (2000). The Public Economics of the Environment. Oxford: Oxford University Press.

Sandmo, A. (2002). 'Efficient Environmental Policy with Imperfect Compliance'. Environmental and Resource Economics, 23: 85-103.

Sandmo, A. (2003). 'International Aspects of Public Goods Provision', in I. Kaul, P. Conceicao, K. Le Goulven and R. U. Mendoza (eds), Providing Global Public Goods. Oxford: Oxford University Press.

Schöb, R. (2003). 'The Double Dividend Hypotheses of Environmental Taxes: A Survey'. CESifo Working Paper, no. 946. Munich: CESifo GmbH.

Stigler, G. J. (1957). 'Perfect Competition, Historically Contemplated'. Journal of Political Economy, 65: 1-17. Reprinted in G. J. Stigler (1965). Essays in the History of Economics. Chicago: The University of Chicago Press.

Whalley, J., and R. Wiggle (1991). 'The International Incidence of Carbon Taxes', in R. Dornbusch and J. M. Poterba (eds), Global Warming: Economic Policy Responses. Cambridge, MA: MIT Press.

Williams, A. (1966). 'The Optimal Provision of Public Goods in a System of Local Government'. Journal of Political Economy, 74: 18-33.

World Bank (2000). World Development Report 1999/2000. New York: Oxford University Press for the World Bank. 